\title{
Business process prioritization criteria: a case study in the financial market
}

\author{
Robson Porfírio dos Santos, Thaiane Martins Salgado and \\ Veridiana Rotondaro Pereira \\ Universidade Presbiteriana Mackenzie, Departamento de Engenharia de Produção, \\ Sao Paulo, Brazil
}

\begin{abstract}
Purpose - This paper aims to analyze and examine how an organization from the financial sector prioritizes its business processes and what criteria are adopted to select the most appropriate process for improvement projects.
\end{abstract}

Design/methodology/approach - This descriptive research is based on an exploratory approach. Qualitative methodology was applied to a case study through on-site observation, documentation analysis and semi-structured interviews.

Findings - The results confirm criteria mentioned in the literature, such as financial aspects and strategic impacts, but also raised a new critical issue: automation potential of manual processes, reflecting the current movement of process automation.

Research limitations/implications - As a limitation of this study, it is worth mentioning the application in only one organization in the financial market and the small number of respondents, even though they occupy leadership positions in the organization.

Practical implications - As a practical implication, the present work offers a direction for managers of the financial sector in structuring and applying models for prioritizing processes aimed at organizational efficiency.

Social implications - Automation solutions for process improvement need careful study to minimize impacts in human resources reduction. In this sense, the eligibility of a process for automation must be carefully considered.

Originality/value - This paper presents the evolution of the process prioritization model adopted by a large institution in the financial market, which has a significant presence in the Brazilian and international markets as a commercial and wholesale bank.

Keywords Prioritization, Financial sector, Business processes management, Improvement projects

Paper type Case study

\section{Introduction}

One of the main objectives of companies is to meet the needs and desires of their customers by offering goods and services and, consequently, generating profit for their owners and

(C) Robson Porfírio dos Santos, Thaiane Martins Salgado and Veridiana Rotondaro Pereira and Veridiana Rotondaro Pereira. Published in RAUSP Management Journal. Published by Emerald Publishing Limited. This article is published under the Creative Commons Attribution (CC BY 4.0) licence. Anyone may reproduce, distribute, translate and create derivative works of this article (for both commercial and non-commercial purposes), subject to full attribution to the original publication and authors. The full terms of this licence maybe seen at http://creativecommons.org/licences/by/4.0/legalcode 
RAUSP

57,1 shareholders (Kahn, 2020; Kreuzer, Röglinger \& Rupprecht, 2020; Weyer, Schmitt, Ohmer \& Gorecky, 2015).

When such companies undergo expansion and increase in market share, they diversify their catalog of products and services to supply a more significant number of potential customers and thus ensure their growth. Offering more products implies creating or improving processes in order to maintain quality, productivity and ensure that, in the end, their consumers have a positive experience, consume again and recommend their products (Carvalho, Maia \& Barbedo, 2012; Favretto, Roman \& Sehnem, 2016; Palvölgyi \& Moormann, 2021; Shukla, Swarnakar \& Singh, 2021).

According to Marques (2018), every company has processes running behind its business, which must be efficient to bring good results, and, therefore, they need to be constantly reviewed and improved. Hammer (2015), in turn, argues that the continuous routine of improving processes is unlikely to have strategic importance for the company as a whole; on the other hand, this routine is likely to result in a massive number of small-scale projects that can be difficult to manage coherently. Thus, it is necessary to understand how to organize, classify and prioritize processes in order to maintain alignment with strategic planning.

Our first two research questions (RQs) derive from this discussion:

$R Q 1$. How does a company prioritize its processes?

$R Q 2$. Is there an area or department responsible for managing the process portfolio?

Despite the relevance of processes, there is still a significant gap in terms of their knowledge and direction in organizations referring this subject in organizations. In 2016, a survey carried out by Harmon (2016) indicated that about $96 \%$ of companies had some processes mapped; however, only $4 \%$ monitored and managed them. It is noteworthy that this gap remains, according to the study carried out in 2020 by American productivity \& quality center (APQC) (Gland, Morgan \& Witt, 2021). The survey indicates that more than $80 \%$ of respondents deemed business process management (BPM) and continuous improvement the top priority for 2021 . These themes stand out even with the growth of contemporary issues such as data analysis (priority for $66 \%$ of respondents) and more classic topics such as project management and strategic planning, priority for $59 \%$ and $58 \%$ of respondents, respectively. Still considering the APQC survey, the biggest challenge is to identify, prioritize and select improvement opportunities on BPM and continuous improvement topics. Thus, our third question arises:

\section{RQ3. How are processes organized and controlled?}

Process prioritization is a critical factor in structuring improvement projects, as well as in enhancing the selection of the best opportunities; it justifies time, effort and resource mobilization to capture benefits as an essential part of the effective management of business processes (Richard, Pellerin, Bellemare \& Perrier, 2021). Thus, we propose two new RQs:

$R Q 4$. What are the criteria adopted for prioritization?

RQ5. What are the results achieved with the prioritization of processes? 
In the financial sector, new technologies (Asad, Mohajerani \& Nourseresh, 2016; Kirakosyan \& Dănăiaţă, 2014), intense competition and constant changes in customer needs (Karpen et al., 2015; Kreuzer et al., 2020; Moormann \& Palvölgyi, 2013) led banks to seek for customer satisfaction not only through good products but also the offering of value through their processes (Palvölgyi \& Moormann, 2021).

Therefore, this article aims to analyze how an organization in the financial sector prioritizes its business processes for improvement projects and what criteria are adopted for such prioritization.

\section{Literature review}

As processes evolve, they follow two paradigms; the first is scientific management, which focuses its efforts on improving production operations, and the second has its origins in the Toyota production system. After Toyotism, there came the quality systems and reengineering. All these management methodologies focused their efforts on process improvement (Davenport, 1993; Paim et al., 2009). Such targeting of efforts occurred because there was a perception that it would bring results to the organization, the customer journey and the market positioning.

Currently, BPM stands out (Pereira, Maximiano \& Bido, 2019) both as a management discipline and a set of technologies supporting process management (Benedict et al., 2013).

Structuring an organization through BPM means a shift in the traditional administration posture. Instead of looking at the individual execution of activities, one begins to understand the execution of all processes globally and dynamically (Thieves, 2001). Improvements in business processes are continuous and achieved through a life cycle (Houy, Fettke \& Loos, 2010), including strategy, modeling, redesign, monitoring and process adjustment (Pereira, Maximiano \& Bido, 2019).

Achieving competitive advantage requires good strategic planning, a process that consists of the systematic analysis of the organization's strengths (competencies) and weaknesses (incompetence or impossibility of improvement) and the opportunities and threats of the external environment, intending to formulate strategies and strategic actions to increase competitiveness and its degree of resoluteness (Vom Brocke \& Rosemann, 2015).

The achievement of business objectives occurs by adopting various actions in different departments, such as employee qualification with training, recruitment, process improvement or adding new technologies. In all these fronts, derived from strategic planning, the project front can monitor project improvement more efficiently.

For project management body of knowledge (PMI, 2017), a project is a temporary effort undertaken to create a unique product, service, or result. Thinking of all the projects that may be running in the organization, the project portfolio emerges, a set of projects grouped for more effective management to achieve the organization's strategies (PMI, 2017).

Portfolio management can be described as an opportunity to map project options that align with the organization's strategies (Padovani, Carvalho \& Muscat, 2010). The ideal portfolio management is that projects are periodically reviewed, analyzing available projects and those already in progress, so that the organization's restrictions are not exceeded to achieve the company's strategies (Archer \& Ghasemzadeh, 1999). According to Padovani et al. (2010), portfolio management occurs at the company's strategic level and aims to identify, select, finance, monitor and maintain the appropriate mix of projects and initiatives. In other words, it is necessary to know which projects to prioritize and balance. For that, one can rely on different criteria.

According to Vargas (2010), project prioritization is about choosing the execution order of a given project in a portfolio, taking into account the cost-benefit ratio. Thus, projects

\author{
Business \\ process \\ prioritization \\ criteria
}

37 
RAUSP

57,1

with more benefits compared to costs should have priority. However, the author also emphasizes that the costs or benefits are not always linked to the financial area, which is the great challenge of prioritizing, i.e. defining cost and benefit. Therefore, it is necessary to define some criteria to make the best possible choice.

According to Ferreira (2017), the criteria for deciding which project to prioritize is based on the values and preferences of those who are choosing them, but, despite this, more specific criteria also enter the balance, such as finances, strategies, risks or threats, urgency, stakeholder commitment and technical knowledge.

In addition to these criteria, there is another contemporary criterion, robotic process automation, which concerns the joining of processes with information technology aiming at "creating uniform, simplified and replicable business processes" (Ferreira, 2017, p. 15), making them more efficient and effective (Silva, 2018). Thus, processes based on rules, predictability, repetitions and dealing with a high volume of data can be automated (Ferreira, 2017; Silva, 2018).

\section{Methodology}

This study aims to analyze how an organization in the financial sector prioritizes its business processes for improvement projects and what criteria are adopted for such prioritization. Thus, to meet this objective, we adopted a qualitative approach and an exploratory strategy, whose nature will allow the observation, analysis and interpretation of the data obtained, focusing on the interpretation of results rather than on their quantification. Furthermore, exploratory research was chosen because it offers familiarity with the problem, making it more straightforward, enabling the construction of hypotheses and improving ideas (Gil, 2019).

In general, studies with the characteristics presented obtain better results by adopting the case study method (Eisenhardt, 1989). Thus, we decided to carry out a case study because this tool makes it possible to analyze a theme observed in reality, explaining how and why it occurs (Yin, 2018).

This study was divided into two stages, the first focused on planning and conducting field research for data collection and the second on structuring the information and analyzing the results obtained, comparing them with the literature. In the data collection stage, a literature search was first carried out on the key themes of the work. Then, the data obtained formed the basis for structuring the interview script.

To select the case to be studied, we searched for a company in the financial segment presenting a formal process of prioritizing processes for eligibility to improvement projects. Thus, we opted for a financial institution with comprehensive performance in the Brazilian market, representative commercial activity in the sector and expressiveness in revenue and number of customers.

As data collection instruments, semi-structured interviews, on-site observation and documental research were carried out, promoting a comparison between the information analyzed during the study and the literature related to the topic. To avoid any information bias, the interviews were conducted individually.

Twelve interviews were conducted with six professionals with extensive experience in the segment and whose characteristics are described in Table 1.

Thus, the research was based on primary sources of information, through data collected in interviews and secondary sources provided by some interviewees, such as annual reports and meeting minutes.

In this context, the immersion through face-to-face meetings and extensive research about the organization allowed us to know the criteria for the prioritization model and which 


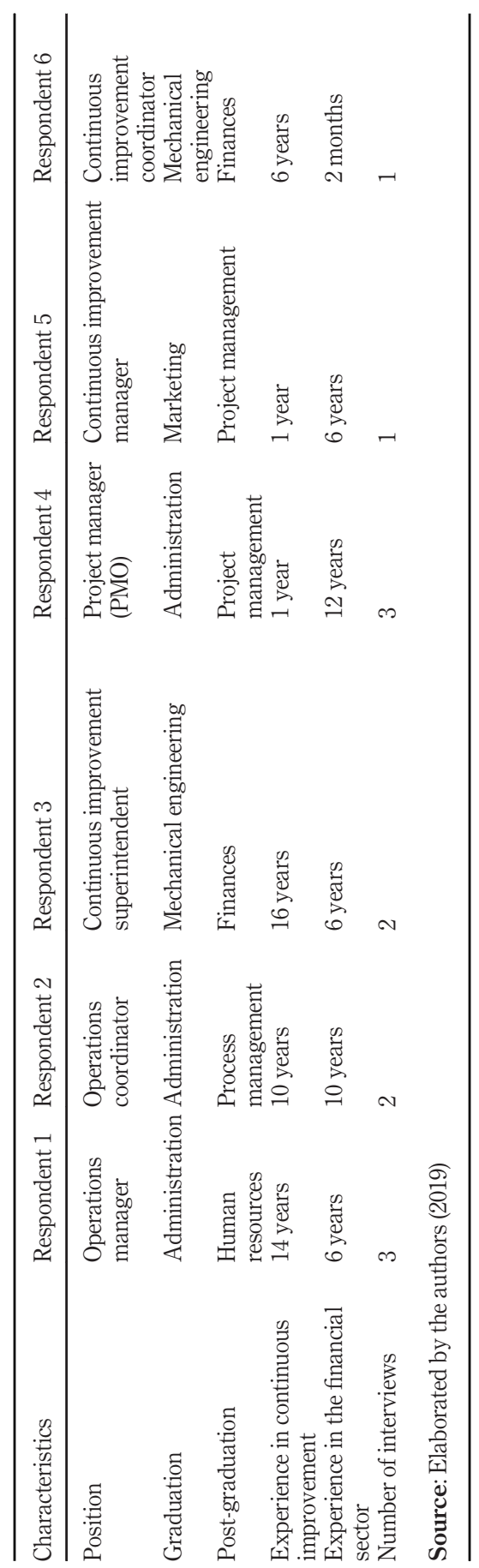

Business process prioritization criteria

39

Table 1. Characteristics of respondents 
RAUSP

57,1

factors, such as hierarchy and strategy, influence, even indirectly, the configuration of such model.

\section{Analysis and results}

\subsection{Organization overview}

For this study, the analysis of the methods used for process prioritization occurred in two stages: the first, in which there is a description of the prioritization model adopted by the company until the first half of 2017, and the second, which addresses the current model until the end of the study analysis.

\subsection{Organization structure and first process prioritization model}

The initial panorama shows the organization structured into two large blocks: the front office, responsible for selling and idealizing new products, and the back office, operationalizing customer purchases and providing support and maintenance of products and services.

From a functional perspective, the back office was structured in two departments, the first dedicated to processing the operations required by retail customers, that is, individuals, and the second, focused on serving the wholesale segment, legal entities. Each board was structured to serve its target audience. We chose to study the retail customers' board, as clients of this segment represent about $60 \%$ of the financial volume transacted by the organization, according to the 2017 annual report.

The retail customers' board organized its operations by product mats, that is, each product had its way of operating, structuring its operations and meeting its demands. In parallel, to ensure operational quality, there was a department whose attributions were to understand customers' needs, monitor the complaints rate, analyze the performance of operations through key performance indicators and promote continuous process improvement using Six Sigma tools.

The promotion of process improvement, in turn, occurred through the use of continuous improvement projects guided by the operational quality area, which sought to understand, with the leaders of the operational mats, gaps and opportunities identified by the deviations from the service level agreement (SLA), indices of complaints in regulatory bodies and by customer expectations when they are in the service channels. This customer expectation will be referred to in this study as customer voice or customer sentiment (Palvölgyi \& Moormann, 2021).

The assertive choice of which process would be analyzed, that is, which process was most likely to have a significant impact on the performance of the operation, resulted from an interview with the managers of the operational conveyors, as they have, in addition to operational knowledge, the sensitivity of the business routine. Figure 1 illustrates this prioritization model, which will be called Model 1.

In Model 1, the so-called prioritization funnel represents the sequence of steps necessary to analyze the processes and rank the ones prioritized to initiate continuous improvement events, in line with the first phase of the BPM life cycle, strategy (Pereira, Maximiano \& Bido, 2019). The area responsible for the improvement cycle activates business and operations managers to understand the business expectations (Asad et al., 2016; Kreuzer et al., 2020) and the operation needs (Hammer, 2015).

Several managers were interviewed, and, consequently, many processes were listed. Based on this understanding, the prioritization process was improved by analyzing the dissatisfaction indicators registered by customers in the call center and listening to their manifestations, following the rank of complaints released quarterly by the Central Bank, 


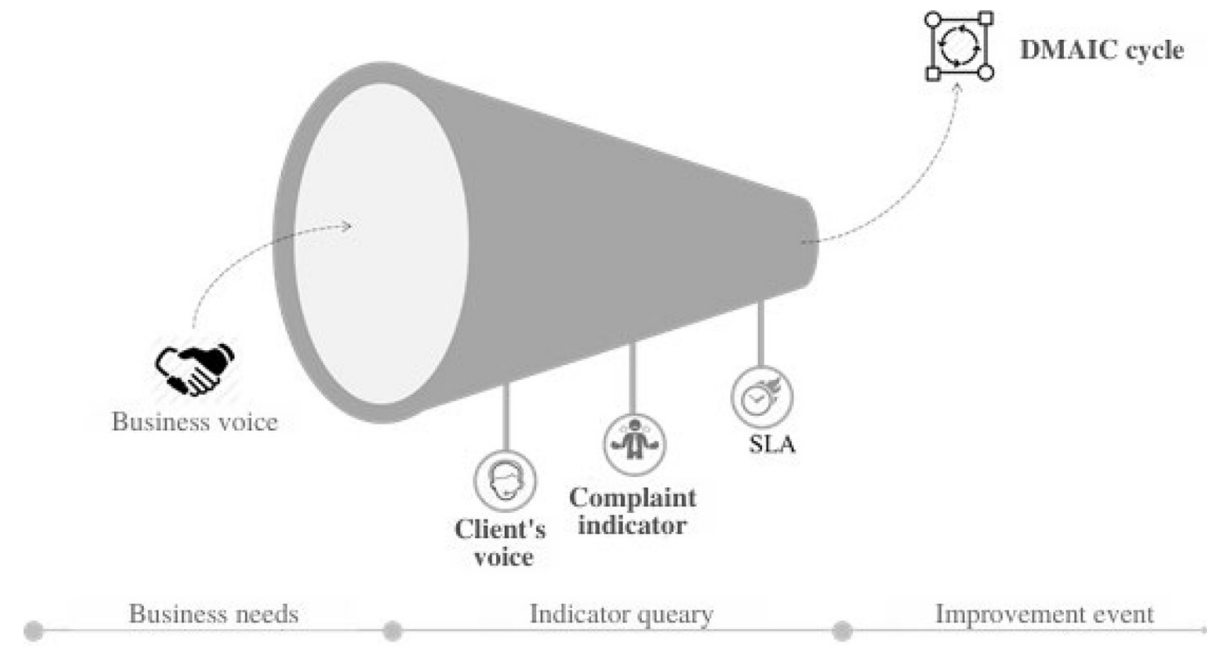

Source: Elaborated by the authors (2019)

\section{Business \\ process \\ prioritization \\ criteria}

41

thus obtaining a comparison with its niche competitors and tracking the performance of key processes through the analysis of the service level or the existing SLA.

The sequence of these steps is part of Model 1 and is presented in Figure 1.

The business voice represented by the interview with managers characterizes a business need (Hammer, 2015), that is, the demands of the manager responsible for the process. The voice of the customer (Asad, Mohajerani \& Nourseresh, 2016; Karpen, Bove, Lukas \& Zyphur, 2015; Kreuzer et al., 2020; Moormann \& Palvölgyi, 2013), the complaint index and SLA - indicators monitored by the quality area - are indices that indicate with a greater degree of assertiveness which of the initially proposed demands should be prioritized to, finally, carry out improvements through the application of the DMAIC method (define, measure, analyze, improve and control).

\subsection{Change in organizational structure and new process prioritization model}

Model 1 valued the operation's performance more than the customer journey, in line to the model prior to reengineering presented by Hammer (2015). The analysis of indicators such as SLA, for example, showed that the process of issuing a real estate credit agreement met the agreed service level, while the client's request was being processed in the back office, but did not include the effective delay; considering that once the product is requested, it is necessary to register it in the real estate registry, among other steps. Given this scenario, the organization promoted a new approach that values customer satisfaction (Kreuzer et al., 2020; Palvölgyi \& Moormann, 2021).

To meet this aim, a new model (Model 2) of back office operations was structured, considering three main action pillars. The first pillar provides for the creation of service platforms responsible for the customer experience throughout the product life cycle and for the development and improvement of new products (Moormann \& Palvölgyi, 2013). The latter was a responsibility of the front office in Model 1.

The second pillar proposes a single processing mat, standardizing these steps as registration, formalization and post-sale follow-up, thus shifting to an industrial processing 
RAUSP

57,1

model. Although, in the previous model, each product had its own operationalizing process, in this new structure, for example, all registration operations, whether rural credit, investment products and cards, must be under the same management to maximize standardization.

Finally, the third pillar stipulates a central area of control and monitoring that measures journey indicators from the customer's point of view, ensures the management of strategic projects, improves processes in the end-to-end consumer journey and consolidates the new operating model. The operational quality area, existing in the old model, merged with other institution areas to create a control platform. The front office, conversely, remains focused on selling products and generating new business.

In line with the organization's strategic objectives, the monitoring and control area remodeled its pillars of analysis and its indicators regarding the performance of operations, valuing four new metrics. The first is the lead time - replacing the SLA - of the customer's life cycle, that is, the time elapsed from the moment the customer contracted a product or service until its effective use; the second, the business conversion rate, is the number of contracts generated from financed vehicles over the amount of vehicle financing simulations performed; the third indicator concerns the rate of errors, rework, failures and operational losses in processing, measured by defects per million opportunities, such as the number of times a rural credit contract went through processing in the back office until it was actually approved. Finally, the unit cost in the processing of each product, that is, the sum of all direct and indirect production costs over the processing volume of the product.

With the indicators defined, the prioritization model proposed by the organization covers three levels: the first refers to the form of input of demands, the second concerns the survey of process characteristics and the third concerns the tools used to promote the process improvement (Figure 2).

The initial prioritization phase is related to the organization's strategy, the direction a company will follow to acquire competitive advantage (Kluyver and Pearce, 2010). The definition originated and disseminated by the strategic level gives the parameters for the processes to be prioritized.

Figure 2. Model 2 process prioritization

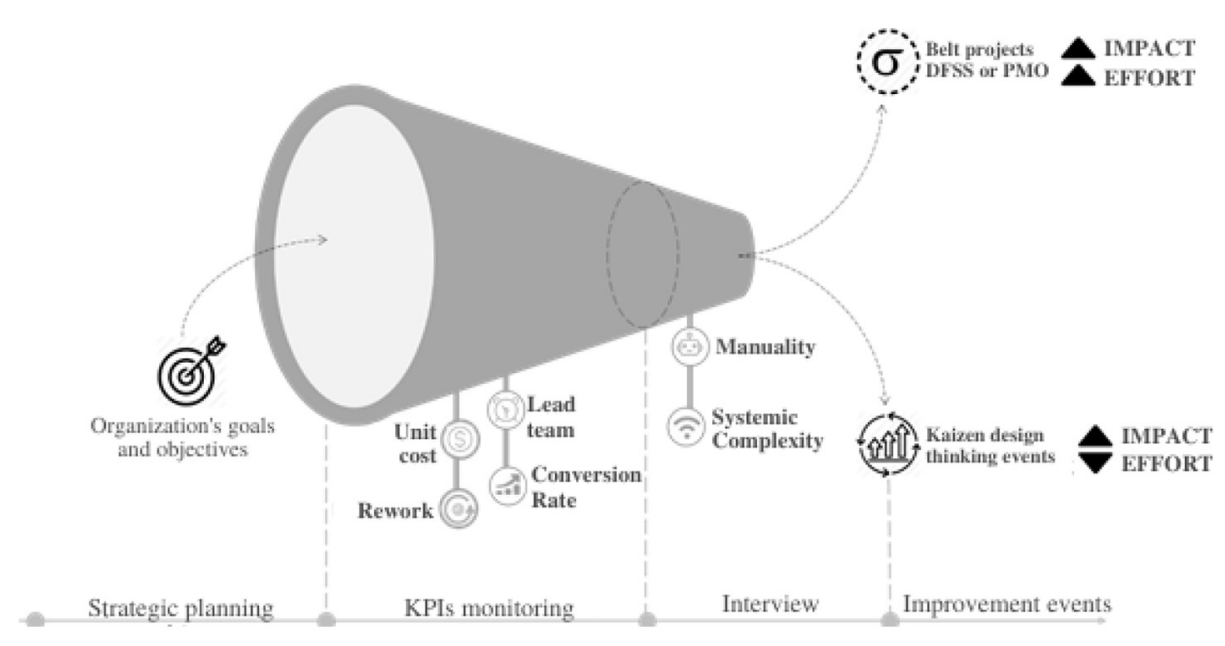

Source: Elaborated by the authors (2019) 
With the guidelines already defined by the organization, including products, processes and goals to be achieved, the indicators of the products or key processes are analyzed according to the metrics agreed upon with the top management. The indicators help to classify the criticality of the processes, considering their emergence and, thus, assess the dimension of the challenges for each of the products and processes prioritized.

To understand thoroughly how processes are operated, an informal interview is carried out with the operation managers as to the manuality, that is, how much the operation depends on people to analyze documents, process files and operationalize systems. In addition, understanding the technological complexity, which concerns the dependence on different systems, sites and databases to complete the operation, is also essential. The main deliverable of this stage is the precise definition of the problem to be explored together with an overview of the process.

Furthermore, it is necessary to identify the best tool to promote continuous improvement. For processes whose focus is on process simplification, without systemic implementations, with low effort and from low to high benefit, short-term improvement projects, about a week, are recommended, such as Kaizen and Design Thinking events, which enables process improvement, with quick implementations to enhance the customer experience. On the other hand, when the results require greater effort and dedication to investigate further the root cause of a problem, green and black belt projects are indicated in which there is immersion in Six Sigma for structuring, analyzing and improving processes.

At the end of the assessment of opportunities, the monitoring and control area is responsible for managing its backlog, which is the list of all processes subject to improvement, and executing continuous improvement events or directing the belt projects to meet the objectives proposed by the organization.

\subsection{Discussion of research questions}

Regarding the RQs proposed in the introduction of this study, a comparative analysis was carried out between Models 1 and 2 of process prioritization, and then the criteria adopted by both were compared with the literature regarding the prioritization of projects:

\section{$R Q 1$. How does a company in the financial sector prioritize its processes?}

To answer this question, we classified the prioritization of processes for improvement projects in the institution studied in four stages: input, assessment, treatment and governance of demands that refer, respectively, to how requests for improvement reach the central area, how they are evaluated, which enhancement tools are applied and how other orders are managed.

The first stage presents the input of processes for improvement. Model 1 brings a segmented assessment of new demands, analyzing the perception of each of the managers, captured through interviews, which may not reflect the organization's objectives, while the second model brings a unified assessment, validated and considered a priority by the leadership of the organization.

As for the assessment of new demands, both models use the existing indicators and references aligned with the organization's strategy as subsidies. However, the second model also deepens analysis, approaching operation managers to understand the dimension of manuality and complexity of the systems involved in processing to assess the effort needed to promote process improvement.

The treatment given to each of the prioritized processes has its own characteristics; the first model uses the DMAIC cycle with a duration of 1-4 months, the same duration and method used by the green and black belt projects in Model 2. This model, as far as it is

\author{
Business \\ process \\ prioritization \\ criteria
}

43 
RAUSP

57,1

concerned, diversifies the catalog of process improvement tools using short-term methodologies, such as Kaizen and Design Thinking, that take place in a week, and methods that demand extensive schedules and complex requirements for execution such as Design for Six Sigma, to achieve disruptive change.

The governance adopted in Model 1 prioritizes new processes only at the end of the DMAIC cycle because there is no waiting list for prioritized processes in this model. On the other hand, Model 2 governance features a queue, also called a backlog, of prioritized processes. This backlog is reviewed in meetings at the management and directive levels to define the continuity of prioritized processes and discuss the entry and priority of new demands. However, it is noticeable that both models present connectivity mechanisms such as knowledge and information exchange, as pointed out by Lizarelli et al. (2018) for process innovation:

\section{RQ2. Is there an area or department responsible for managing the process portfolio?}

Yes, in both models presented, there was a central area responsible exclusively for process management. In parallel to the project management, this central area approaches the project management office that standardizes project governance processes and facilitates sharing resources, methodologies, tools and techniques (PMI, 2017). In the interview, Respondent 1 said that he entered the studied institution intending to structure this area with an exclusive focus on management, given his vast experience in the industrial world and the application of continuous improvement, which reflects the industrialization of services as a competitive advantage (Richard et al., 2021):

\section{RQ3. How are processes organized and controlled?}

Regarding the organization, in the first model, according to the reengineering precepts of Hammer (2015), there is vertical management in which each process is designed according to the product's needs. On the other hand, the second model follows horizontal management, one of the BPM premises, covering the entire value chain, delivering more value to the customer and the organization's core objectives.

Respondents were unanimous about the efficiency of the second model for process management. Respondent 3, part of the senior leadership, pointed out that the new model reduces redundancy since the registration process, regardless of the product, is similar, generating efficiency and fluidity. Respondent 2 , who works directly with the analysts who carry out the operations, said that this model facilitates the understanding and responsibility of each one in the process, contributing with greater significance to the activities involved:

\section{RQ4. What criteria are adopted for prioritization?}

By emphasizing the prioritization of projects, Vargas (2010) highlights that the order of execution of the projects contained in a portfolio considers the fundamentals, values and preferences of those who are choosing them.

Model 1 includes as prioritization criteria: critical indicators - complaints, indicators and the "voice of the customer," besides the so-called "voice of the business," represented by the objectives of the product managers. By comparing both process portfolio management criteria applied by the financial institution with the project portfolio management model, we found that there is equivalence in the urgency of the demand for managers, according to the criticality raised through the interview, and the cycle of improvement is carried out through the genuine commitment between the interested parties. 
Model 2, in turn, has as input the processes following the objectives and goals stipulated by the organization, and as a form of evaluation, it weights the unit cost of the processes, equivalent to the strategic and financial criteria cited by Vargas (2010). However, the interview with the process manager during the prioritization funnel highlights another criterion aimed particularly at processes: its manuality and the potential for automation via robotic process automation (RPA) that it presents.

Unlike the other criteria already mentioned, in selecting priority projects, automation via RPA is adopted exclusively for prioritizing processes. It concerns the combination of processes with information technology (systems and information), thus enabling many administrative activities to be handled through integrated algorithms (Ferreira, 2002). This criterion is in line with the need for new technologies (Asad, Mohajerani \& Nourseresh, 2016; Kirakosyan \& Dănăiață, 2014).

Table 2 presents a summary of the comparison between the two models.

When we questioned the respondents about the particularity of manuality as a criterion for prioritization, the answer was that this type of solution is low cost, simple to implement and has high impact, being, therefore, consistent with the objectives of the continuous improvement tools (Benedict, Bilodeau, Vitkus, Powell, Morris, Scarsig \& Furlan, 2013):

RQ5. What results have occurred with process prioritization?

The application of this new model (Model 2) allowed the organization to select strategic processes whose improvements showed a $42 \%$ reduction in rural credit issuance time; more than $50 \%$ efficiency in lead time when hiring a vehicle consortium; and $44 \%$ reduction in the volume of back office requests and requests from high-income customers.

Respondent 6 reports that the expressive results stem from the commitment of the top leadership, which requires the engagement of the entire hierarchy. Respondents 2 and 4, who have been in the financial market longer, add that direct assignment of process owners, rather than a specific product, as in Model 1, facilitates cooperation. In short, the additional comments of all respondents point to the benefits attributed to the implementation of process-oriented management.

\section{Conclusion}

The main objective of this study was to identify how an organization in the financial sector prioritizes its improvement project processes $(R Q 1)$, seeking to understand which structures $(R Q 3)$, controls $(R Q 4)$ and criteria $(R Q 2)$ were used and whether these variables matched the literature on prioritization criteria for projects and, finally, what impacts they caused (RQ5).

\begin{tabular}{lccr}
\hline Criterion & Model 1 & Model 2 \\
\hline Financial & - & $\checkmark$ & \\
Strategic & - & $\checkmark$ & \\
Risks or threats & - & - & Table 2. \\
Urgency & $\checkmark$ & - & Comparison between \\
Commitment of interested parties & $\checkmark$ & - & project and process \\
Technical knowledge & - & & prioritization criteria \\
RPA automation manuality & - & & \\
Source: Elaborated by the authors (2019) & & & \\
\hline
\end{tabular}

\section{Business process prioritization criteria}

45

\section{$+2$}


RAUSP

57,1

Regarding the objective of comparing these criteria identified in the prioritization of processes to those in the literature, we found that the criteria of strategic alignment, financial resources, urgency and stakeholder commitment are factors present in eligibility, whether in the approval of a project or choosing a process for improvement. However, in both models presented, risks, threats or technical knowledge, criteria present in the prioritization of longer term and highly complex projects, were not decisive factors for choosing a process. In contrast, the eligibility of a process for automation via RPA was identified as a specific criterion for improving a process given the high return and low effort compared to large systemic developments, being conducive to short- to medium-term improvements.

As a practical implication, the present work offers a direction for managers of the financial sector in structuring and applying models for prioritizing processes aimed at organizational efficiency.

As a limitation of the study, it is worth mentioning the application in only one organization in the financial market, and the small number of respondents, even though they occupy leadership and visibility positions in the organization.

Therefore, for future research opportunities, it is advisable to analyze other financial institutions to verify whether the models and criteria presented in this study are a trend for process management in this field and whether other internal and external criteria or factors influence these organizations. Based on this study, quantitative research can be carried out to fill gaps and present a robust process prioritization model.

\section{References}

Archer, N. P., \& Ghasemzadeh, F. (1999). An integrated framework for project portfolio selection. International Journal of Project Management, 17(4), 207-216, available at: https://doi.org/ 10.1016/S0263-7863(98)00032-5

Asad, M. M., Mohajerani, N. S., \& Nourseresh, M. (2016). Prioritizing factors affecting customer satisfaction in the internet banking system based on cause and effect relationships. Procedia Economics and Finance, 36, 210-219, available at: https://doi.org/10.1016/S2212-5671(16)30032-6

Benedict, T., Bilodeau, N., Vitkus, P., Powell, E., Morris, D., Scarsig, M. and Furlan, J. (2013). BPM CBOK version 3.0: Guide to the business process management common body of knowledge: CreateSpace/ABPMP, Association of Business Process Management Professionals.

Carvalho, T. F., Maia, M. V., \& Barbedo, C. H. S. (2012). O efeito da diversificação no valor das empresas listadas em bolsa no brasil. RAM. Revista de Administração Mackenzie, 13(1), 87-109.

Davenport, T. H. (1993). Process Innovation: Reengineering Work through Information Technology, Boston, MA: Harvard Business School Press.

Eisenhardt, K. M. (1989). Building theories from case study research. The Academy of Management Review, 14(4), 532-550, doi: https://doi.org/10.2307/258557.

Favretto, J., Roman, D., \& Sehnem, S. (2016). Análise dos recursos impulsionadores da vantagem competitiva - o caso BRF foods. Revista Gestão da Produção Operações e Sistemas, 11(3), available at: https://doi.org/10.15675/gepros.v11i3.1477

Ferreira, A. (2002). Gestão empresarial de taylor aos nossos dias: evolução e tendências da moderna administração de empresas, São Paulo: Pioneira Thomson Learning.

Ferreira, A. F. R. (2017). A cadeia de valor e os modelos de business process outsourcing (BPO): modelos de negócio na oferta Portuguesa de serviços outsourcing. (mestrado, Universidade Nova de Lisboa.

Gil, A. C. (2019). Métodos e técnicas De pesquisa social, 7a ed., São Paulo: Atlas. 
Gland, H. L. H., Morgan, L., \& Witt, N. (2021). 2021 Process \& performance management priorities \& challenges, available at: Retrieved from www.apqc.org

Hammer, M. (2015). What is business process management?. In J. Vom Brocke, \& M. Rosemann, (Eds), Handbook on business process management 1, 2nd ed., Heidelberg: Springer.

Harmon, P. (2016). The state of business process management, Retrieved from www.bptrends.com/bpt/ wp-content/uploads/2015-BPT-Survey-Report.pdf

Houy, C., Fettke, P., \& Loos, P. (2010). Empirical research in business process management - analysis of an emerging field of research. Business Process Management Journal, 16(4), pp. 619-661, doi: https://doi.org/10.1108/14637151011065946.

Kahn, B. (2020). Research priorities 2020-2022. MSI - Marketing Science Institute, 13Acesso em: 24/04/ 2021.

Karpen, I. O., Bove, L. L., Lukas, B. A., \& Zyphur, M. J. (2015). Service-dominant orientation: measurement and impact on performance outcomes. Journal of Retailing, 91(1), 89-108, available at: https://doi.org/10.1016/j.jretai.2014.10.002

Kirakosyan, K., \& Dănăiată a. D. (2014). Communication management in electronic banking. Better communication for better relationship. Procedia - Social and Behavioral Sciences, 124, 361-370, Retrieved from https://doi. org/10.1016/j.sbspro.2014.02.497

Kluyver, C. A. D., \& Pearce, J. A. II. (2010). Estratégia: uma visão executive, 3 ed., São Paulo: Pearson Education do Brasil.

Kreuzer, T., Röglinger, M., \& Rupprecht, L. (2020). Customer-centric prioritization of process improvement projects. Decision Support Systems, 133, 113286, Retrieved from https://doi.org/ 10.1016/j.dss.2020.113286

Lizarelli, F., Toledo, J., \& Alliprandini, D. (2018). Integration mechanisms for different types of innovation: case study in innovative companies. Review of Business Management, 21(1), 5-32, Retrieved from https://doi. org/10.7819/rbgn.v0i0.3958

Marques, J. R. (2018). Projeto de melhoria de processos e outros pontos: como fazer e aplicar?. Acesso em: 2019.

Moormann, J., \& Palvölgyi, E. Z. (2013). Customer-Centric Business Modeling: Setting a Research Agenda. Paper presented at the 2013 IEEE 15th Conference on Business Informatics.

Padovani, M., Carvalho, M. M. D., \& Muscat, A. R. N. (2010). Seleção e alocação de recursos em portfólio de projetos: estudo de caso no setor químico. Gestão \& Produção, 17(1), 157-180. doi: https://doi. org/10.1590/S0104-530X2010000100013.

Paim, R., Cardoso, V., Caulliraux, H., \& Clemente, R. (2009). Gestão de processos: pensar, agir e aprender, Porto Alegre: Bookman.

Palvölgyi, E. Z., \& Moormann, J. (2021). Customer process-centric artefacts: a literature review. Business Process Management Journal, 27(2), 615-637, doi: https://doi.org/10.1108/BPMJ-07-2020-0328.

Pereira, V. R., Maximiano, A. C. A., \& Bido, D. D. S. (2019). Resistance to change in BPM implementation. Business Process Management Journal, 25(7), 1564-1586, doi: https://doi.org/ 10.1108/BPMJ-07-2018-0184.

PMI. (2017). A guide to the project management body of knowledge (PMBoK guide), 6th ed., Newtown Square, PA, Estados Unidos: Four Campus Boulevard.

Richard, S., Pellerin, R., Bellemare, J., \& Perrier, N. (2021). A business process and portfolio management approach for industry 4.0 transformation. Business Process Management Journal, 27(2), 505-528, doi: https://doi.org/10.1108/BPMJ-05-2020-0216.

Shukla, V., Swarnakar, V., \& Singh, A. R. (2021). Prioritization of lean six sigma project selection criteria using best worst method. Materials Today: Proceedings, Retrieved from https://doi.org/ 10.1016/j.matpr.2021.04.038

Silva, J. F. M. (2018). O impacto da automatização e inteligência artificial nos serviços partilhados. Dissertação de Mestrado, Universidade do Porto, Porto. 
RAUSP

57,1
Thieves, J. J. J. (2001). Workflow - Uma tecnologia Para transformação do conhecimento nas organizações, 2nd ed., Florianópolis: Insular.

Vargas, R. V. (2010). Utilizando a programação multicritério (Analytic Hierarchy Process - AHP) para selecionar e priorizar projetos na gestão de portfólio. Paper presented at the PMI Global Congress, Washington, DC.

Vom Brocke, J., \& Rosemann, M. (2015). Handbook on Business Process Management 1, 2nd ed., Heidelberg: Springer.

Weyer, S., Schmitt, M., Ohmer, M., \& Gorecky, D. (2015). Towards industry 4.0 - Standardization as the crucial challenge for highly modular, multi-vendor production systems. IFAC-PapersOnLine, 48(3), 579-584, Retrieved from https://doi. org/10.1016/j.ifacol.2015.06.143

Yin, R. K. (2018). Case Study Research and Applications: Design and Met, 6th ed., Los Angeles: Sage Publications.

Author contributions are as follows: Robson Porfirio: conceptualization (equal), data curation (equal), formal analysis (equal), investigation (equal), methodology (equal), project administration (equal), validation (equal), writing - original draft (equal), writing - review and editing (equal); Thaiane Martins Salgado: conceptualization (supporting), data curation (supporting), formal analysis (supporting), investigation (supporting), methodology (equal), project administration (equal), validation (supporting), visualization (supporting), writing - original draft (equal), writing - review and editing (equal); Veridiana Rotondaro Pereira: conceptualization (equal), data curation (supporting), formal analysis (equal), investigation (supporting), methodology (supporting), project administration (supporting), supervision (lead), validation (equal), visualization (equal), writing - original draft (supporting), writing - review and editing (equal).

\section{Corresponding author}

Veridiana Rotondaro Pereira can be contacted at: rotondaro.veridiana@gmail.com

Associate editor: Carlos Sato

For instructions on how to order reprints of this article, please visit our website: www.emeraldgrouppublishing.com/licensing/reprints.htm Or contact us for further details: permissions@emeraldinsight.com 